\title{
O enigma da atividade humana convoca clínicas do trabalho
}

Daisy Moreira Cunha ${ }^{1}$

\section{Resumo}

O texto apresenta interrogações, problemas e compartilhamentos epistemológicos comuns entre dois dos principais autores da Abordagem Ergológica do Trabalho (Yves Schwartz) e da Clínica da Atividade (Yves Cot) por meio de revisão conceitual e teórico-metodológica de suas principais contribuições. Neste resgate, verificamos que compartilham uma problemática teórica relativa ao lugar do homem produtor nas situações de trabalho. Entretanto, observamos que, mesmo partindo de fontes teóricas comuns, em virtude de uma tensão no tratamento dos termos centrais desta problemática - atividade-subjetividade-meio, estes autores se distanciam pelos diálogos teóricos que trazem ao debate no percurso de sua investigação.

Palavras-chave: Abordagem Ergológica do Trabalho; Clínica da Atividade; Trabalho; Atividade.

\section{L'énigme de l'activité humaine appelle des cliniques de travail}

\section{Résumé}

Le texte présente les questions, problèmes et partages épistémologiques communs entre deux des principaux auteurs de l'Approche Ergologique du Travail (Yves Schwartz) et de la Clinique de l'Activité (Yves Cot) à travers une revue conceptuelle et théorico-méthodologique de leurs principales contributions. Dans cette récupération, nous avons constaté qu'ils partagent une problématique théorique concernant la place de l'homme producteur dans les situations de travail. Cependant, nous observons que, même à partir de sources théoriques communes, en raison d'une tension dans le traitement des termes centraux de cette problématique - activité-subjectivité-moyen, ces auteurs sont distancés par les dialogues théoriques qui apportent au débat au cours de leurs recherches.

Mots-Clés: Approche ergonomique du travail ; Clinque de l'Activité; Travail; Activité.

\section{Introdução}

Na defesa de doutoramento de Yves Clot (26 de novembro de 1992), sob orientação de Yves Schwartz, a Professora Paule Monique Vernes, então presidente da banca, demarcou o seguinte compartilhamento de reflexões:

A leitura atenta de 855 páginas da tese de Yves Clot (mais 30 páginas de bibliografia) é um trabalho real para quem não está integrado nisso que o autor nomeia, em the consagrando um capítulo,"um meio filosófico", isto é, o Departamento de Ergologia da Universidade de Aix-en-Provence, pesquisa em APST - Análise Pluridisciplinar sobre Situações de Trabalho. Esse "meio" parece ter fornecido a ele o essencial de seu objeto e é preciso interpretar a onipresença da obra de Yves Schwartz, quer seja citado, explicitamente, ou que

\footnotetext{
${ }^{1}$ Universidade Federal de Minas Gerais /UFMG, Belo Horizonte, daisycunhaufmg@gmail.com.
} 
seu pensamento corra, implicitamente, sob o texto, como uma maneira simpática de pagar suas dívidas (VERNES et al., 1992, p.1). ${ }^{2}$

Em que pese o interesse comum sobre a atividade industriosa (SCHWARTZ, 1992), uma diferenciação/tensão entre atividade-subjetividade na tese de Yves Clot distanciará os dois pensadores. Clot funda na dialética das formas estes dois termos como dimensões distintas e interrelacionadas:

o poder das formas simbólicas não provém justamente de sua capacidade de tirar a realidade de suas contradições? De sua capacidade de responder precisamente à força dos conflitos reais? Se é este o caso, o simbólico fará parte da realidade num duplo sentido: em primeiro lugar, porque é parte integrante dela. Melhor dizendo, porque, na produção dialética das formas em que o real se engendra, ele marca o seu próprio modo de desenvolvimento. Ele é uma das formas nas quais, ao mesmo tempo, se depura e se promove o movimento real. Mas em seguida, eu diria inversamente, porque ele é constituído de contradições da história real, literalmente habitado pelos antagonismos exteriores onde ele se realiza. Nosso trabalho procurou pensar conjuntamente a oposição e a identidade entre o real e o simbólico, tentando substituir a articulação de "esferas" exteriores uma a outra pela compreensão dialética das formas [...] o social é feito de relações, é parte integrante da subjetividade, na medida em que a submete sempre à prova dos conflitos que o afetam (CLOT, 1987, p.305).

Yves Schwartz (Abordagem Ergológica do Trabalho) e Yves Clot (Clínica da Atividade) compartilham problemas, interrogações comuns e muitos fundamentos teórico-metodológicos, desde os anos 80. Em meio a uma cultura acadêmica bastante disciplinar, trilham territórios epistêmicos distintos, filosofia e psicologia respectivamente, buscando evidenciar o que se passa nas nervuras do trabalho real. Esse problema os convoca permanentemente ao trabalho interdisciplinar.

Constatamos, entretanto, um diálogo surdo, marcado por confrontações pontuais, com muitas complementaridades, recobrimentos conceituais e metodológicos para compreender o

\footnotetext{
${ }^{2}$ la lecture attentive de 855 pages de la thèse d'Yves Clot (plus 30 pages de bibliografie) est un véritable travail pour qui n'est pas intégré dans ce que l'auteur nomme en lui consacrant un chapitre 'un milieu philosophique', c'est-àdire le centre APST-Recherche d'Aix-en-Provence. Ce 'milieu semble lui avoir fourni l'essentiel de son sujet et il faut interpréter l'omniprésence de l'ouvre d'Yves Schwartz, qu'il soit cité explicitement ou que sa pensée courre implicitement sous le texte, comme une manière sympathique de payer ses dettes (Rapport sur la thèsed'YvesClot,p.1) (VERNES et al., 1992, p.1).
} 
enigmático trabalho humano.O encontro/desencontro das abordagens desses dois autores, forjando compreensões sobre o trabalho e sobre o homem produtor requer confrontação cruzada entre os próprios teóricos supracitados. O que faremos, neste artigo, é, no curso de suas trajetórias específicas e sem preocupação cronológica, explorar compartilhamentos que se mostraram vitais para estruturação de suas hipóteses de trabalho desvelando convergências e divergências.

\section{Forjando clínicas do trabalho}

O contexto societário que marca o nascimento dessas“ clínicas francesas do trabalho" (BENDASSOLLI; SOBOLL, 2011) é aquele do Estado de Bem-Estar na França dos anos 80, com forte estruturação do campo dos Direitos Civis, Políticos e Sociais, em especial o Direito à Educação, à Saúde e ao Trabalho. Entretanto, desde a década de 70, evidenciam-se, tanto os efeitos nefastos do taylorismo para a saúde dos trabalhadores quanto a reestruturação produtiva com a emergência dos modelos de gestão pela qualidade e a introdução de novas tecnologias na produção de bens e serviços. Momento de grandes mutações socioeconômicas, políticas, éticas e no campo da produção de conhecimento.

É também momento em que emerge uma crítica a todo tipo de objetivismo estrutural ou materialismo neuronal, recolocando temas ligados ao indivíduo singular, à personalidade e à subjetividade humana, considerada na sua globalidade como "resultante dos processos pelos quais o indivíduo, em estreito contato com as estruturas simbólicas da cultura humana, tenta assumir e abrir um acesso à forma genérica de seu ser" (DORAY, 1987, p.85). Um vasto terreno se abre de onde se indaga processos de formação identitária dos indivíduos, suas dimensões subjetivas, imaginárias e simbólicas, ou seja, "o estatuto da subjetividade na história biográfica e social" (CLOT, 1987, p, 190). Nesta perspectiva o sujeito volta à cena da reflexão acadêmica como "chave de inteligibilidade e ator da humanidade" por meio de uma abordagem nos campos de estudos das Histórias de Vida, das abordagens autobiográficas, entre outros. É nesta linhagem onde se enraízam as reflexões e hipóteses de trabalho de Yves Schwartz e Yves Clot, delimitadas na coletânea Je, sur l'individualité humaine, da qual participam Lucien Sève, Michèle Bertrand, Bernard Doray, Antoine Casanova, Françoise Hurstel, Jean-Pierre Terrail.

A obra resulta de reflexões no âmbito dolnstitut de Recherches Marxistes, fundado em 
1983, e se inscreve na linhagem do trabalho pioneiro de Lucien Sève, Marxismes et Théorie de la Personalité (1969), discutindo a gestação da personalidade no terreno das configurações sociais com base na VITese de Feuerbach: "A essência humana não é uma abstração inerente ao indivíduo singular. Em sua realidade é o conjunto das relações sociais" (MARX apud LABICA, 1987). Sève se inspira largamente em Georges Politzer (Critique des Fondements de la Psychologie, 1929; La crise de la Psichologie contemporaine, 1928) que, com base em Marx, propõe analisar as condições sociais do drama humano, encrustrando-o no mundo real da vida na economia, na história coletiva. Seria necessário fundar uma psicologia concreta do drama entranhada nas relações sociais cujos desenvolvimentos evidenciam a importância dos estudos biográficos. Esta orientação geral leva a considerar uma dialética dos possíveis, na qual se "tece o patrimônio excentrado de uma humanidade onde viver ganha sentido singular para cada um" (CLOT, 1987, p.306).

Herdeiros em diálogo com Marx, em que pesem suas diferenças teórico-metodológicas, os autores de Je, sur l'individualité humaine interrogam-se quanto às possibilidades de compreender questões relativas à subjetividade humana, pelo escasso investimento de Marx no entendimento das formas concretas de trabalho, dando maior visibilidade ao engendramento do trabalho abstrato. Na obra O Capital, Marx, apesar de reconhecer e sublinhar a diferenciação entre trabalho concreto e trabalho abstrato, enfatizará os caminhos da formação dos valores econômicos, caminhos nos quais todo trabalho concreto vai sendo subsumido no processo de formação do trabalho abstrato no capitalismo. A questão que unifica esses oito autores é, portanto, que tipo de tratamento dar ao sujeito no marxismo sem

escolher o objeto contra o sujeito, o histórico contra o biográfico, o material contra o simbólico e o mutável contra o invariante [...] é justamente compreender, em se colocando do ponto de vista da prática humana, essa atividade inseparavelmente objetiva e subjetiva, reversível e irreversível onde se nucleiam as relações dialéticas dessas realidades distintas mais conexas ponto de vista fora do qual a gente se expõe a não extrair delas somente seu simulacro abstrato (SÈVE, 1987, p.9). ${ }^{3}$

Os autores aparecem debatendo com Marx, na contramão das grandes correntesanti-

\footnotetext{
${ }^{3}$ Choisir l'objet contre le sujet, I'historique contre le biographique, le materiel contre le symbolique et le muable contre l'invariant, mais c'est justement les com-prendre en se plaçant du point de vue de la pratique humaine, cette activité inséparablement objective et subjective, reversible et irreversible où se nouent les rapports dialectiques de ces réalités distinctes mais connexes - point de vue hors duquel on s'expose à ne saisir d'elles que leur simulacra abstrait (SÈVE, 1987, p.9).
}

Periódico Horizontes - USF - Itatiba, SP - Brasil - e021030 
humanistas e estruturalistas que assolam as ciências humanas, desde osanos 60, na França. Essas teses anti-humanistas são fortemente discutidas por Schwartz (1988) como sendoperspectivas, nas quais o ato de trabalho poderia ser compreendido comodado a partir de normas prescritas pelos gestores do trabalho taylorista, pelo "Aparelho Ideológico do Estado" (Althusser) e/ou "prática socialmenteconstituída" (Bourdieu). Nestas perspectivas anti-humanistas o peso das estruturas invoca um"sujeito-produto". Ao contrário, os autores do livro Je, sur l'individualité, compartilham a ideia de que as estruturas sociais podem explicar somente em parte os aspectos relacionados à subjetividade humana. É preciso compreender o EU no campo concreto das atividades humanas, o trabalho figurando como uma experiência a ser considerada, centralmente.

Constata-se um horizonte comum de contrapontos com Marx, onde o real é compreendido como síntese de múltiplas determinações, bem como nas críticas contundentes às correntes estruturalistas. Entretanto, as diferenças de orientação téorico-metodológicas entre os oito autores da coletânea fundam-se em tensões relativas às formas históricas da individualidade social e a forma social da individualidade. Enquanto Lucien Sève interroga em que a obra marxiana permite compreender a gestação da personalidade, Bernard Doray (DORAY, 1989, p.85) busca reunir elementos para uma teoria da subjetividade "entendida como conjunto de processos pelos quais o indivíduo, em estreito contato com as estruturas simbólicas da cultura humana, tenta abrir acesso à forma genérica de seu ser", desvelando suas estruturas elementares, dialogando com saberes sobre a realidade psíquica (inclusive com a psicanálise): "o marxismo, por levar em conta os homens reais, deve aprender a assimilar de maneira crítica o que a psicanálise nos ensina sobre a subjetividade" (DORAY, 1989, p.108). Lucien Sève, por sua vez, fala de "descentramento", levando às últimasconsequências a VI Tese de Feuerbach (Marx), tentando pensar aideia de "descentramento" da essência humana nas "formas históricas de individualidade". Em entrevista a mim concedida ${ }^{4}$ (2002) sobre sua obra, Lucien Sève reafirma que,afinal, Vygotski terá realizado magistralmente seu projeto. Já Schwartz, em seu capítulo Usage de soi, nos convidaa pensar que, se há "descentramento", há, também, "recentramento" permeando toda relação homem-meio de vida etrabalho. Há aqui um resgate da filosofia de

\footnotetext{
${ }^{4}$ SÈVE, Lucien. [Actualité du débat Marxisme et théorie de la personnalité]. [Entrevista cedida a Daisy Moreira Cunha]. Paris, 2002. 1 fita cassete.
}

Periódico Horizontes - USF - Itatiba, SP - Brasil - e021030 
Georges Canguilhem, possibilitando pensar que todo homem quer ser sujeito de suas próprias normas. Tal "recentramento" se expressa num "uso de si", um "si" queseria preciso, obviamente, investigar melhor, pois ele implica algo maiscomo uma atividade vital que recompõe o mundo à sua conveniencia (SCHWARTZ, 2000c, p.44). Esse "si" é compreendido como resultado de umarelação do indivíduo-meio, onde o indivíduo apresenta a"capacidade de criar novas normas de vida em confrontação com o meio,a consciência de um mau uso e a reivindicação de outro uso conformeaos seus possíveis singulares" (SCHWARTZ, 2000c, p.44).

Nessa perspectiva teórica aberta por Schwartz, na esteira deGeorges Canguilhem (1947; 1995), não há apenas reiteração das formas de vida jáexistentes, há um dinamismo vital que organiza a relação homem-meio no plano singular que somente pode ser compreendido por umaclínica. A institucionalização de uma norma social é o estabelecimento de um parâmetro de valor de certas formas de vida, oque vem a ser formas de regulação social que racionaliza, regula,disciplina, ou seja, acaba por representar, por sua exterioridade àsingularidade do indivíduo, valor arbitrário e transcendente. O normalnão é um conceito prefixado à vida, dirá Yves Schwartz, reforçando os pressupostos da Filosofia da Vida (Georges Canguilhem) para a qual o normal é a plasticidade da vida e suas múltiplas possibilidades de ser vivida: "O normal é a vida enquanto impossível de ter todas as suas formas predicadas já de saída [...] o normal da vida é de ser normativa" (NEVES, PORCARO, CURVO, 2017, p.633).

Nem o meio pode ser tomado como invariável, nem a vida pode não sernormativa. Ela não cabe em normas pré-estabelecidas, mas extrapola,desvirtua, transborda e tenta criar o mundo à suas próprias normas. Porisso, sabemos que a saúde é uma construção nas possibilidades abertaspela interação com o meio, onde podemos entrever os processos designificação sobre a concretude da vida. Essa interatividade é mediadapelos valores do organismo nas interfaces organizacionais, técnicas einterativas que se apresentam nas situações de trabalho no que elas trazem em si de estrangeiro ao indivíduo, de aleatório, de acaso e de contingente, tornando a vida arriscada em meio infiel. A vida é "atividade de oposição à inércia e à indiferença [...] joga contra a entropia crescente" (CANGUILHEM, 1995, p.208). A ideia de saúde em Canguilhem traz consigo a compreensão de que ser normal é ser capaz de interagir com o meio cambiante e infiel, tolerar suas infrações ao que se está habituado e buscar novas normas reconfigurando as situações. A saúde é essa tolerância adaptativa que possibilita intervir, 
transformando o meio conforme seus propósitos.

Essa concepção de saúde convoca ao estudo do trabalho por meio de uma abordagem clínica, mas que pressupõe uma compreensão profunda da história, do contexto. Tudo se passa em um momento histórico e situado. Na contemporaneidade, Schwartz (2000a) demarca o Espaço Tripolar de sociedades mercantis de Direito, uma vez que existem aí valores mercantis e valores do bem comum pré-configurando e se debatendo, em permanência, nas situações de trabalho que analisamos. Não podemos compreender uma situação de trabalho fora do contexto meso das empresas/instituições e macro dos setores e mercados de trabalho nas quais se insere. Nesse contexto, também devemos considerar as relações de emprego de todos e de cada um, o que reenvia, por seu turno, ao sistema educativo eàs trajetórias possíveis nele, reenvia aos demais direitos sociais, aos modos de relações profissionais e à história específica de cada país, de cada empresa, de cada local de trabalho... E assim sendo, a Ergologia não é uma "clínica do trabalho" apenas, mas, antes, uma clínica da vida que pode ser (entre)vista pelo encontro com a atividade de trabalho real.

\section{A singularidade da experiência}

A singularidade da experiência vivida por cada trabalhador é aspecto central na obra de Ivar Oddone em Reconnaître l'ExpérienceOuvrière, cuja tradução francesa é apresentada por Yves Clot, em 1981, e reivindicada pelos dois autores que discutimos neste artigo, cada qual se apropriando e desenvolvendo aspectos centrais ecombinados em suas abordagens. Yves Clot aprofunda o dilema de expressão da experiência do trabalho a partir do método de Instrução ao Sósia (ODDONE, RE, BRIANTE, 1981), que visava compreender os sentidos atribuídos pelos trabalhadores ao que viviam, faziam, pensavam e portavam em suas lutas, enquanto operários metalúrgicos na FIAT da Turim dos anos 70. Os trabalhadores eram convidados a fornecer Instruções a um Sósia, de modo que este, ao substituí-lo, executasse as tarefas de trabalho com tanto zelo aos detalhes que não fosse percebido nem pelos colegas, nem pela chefia. Esses depoimentos favorecem uma tomada de consciência daqueles que narram suas formas de trabalhar, ao trazer à consciência os meandros e as interfaces do trabalho para o próprio trabalhador, estimulando a reflexão sobre os problemas quotidianos que enfrentam nas situações 
de trabalho nas quais se encontram. Esse processo, altamente educativo para aquele que trabalha, tem potencial para se configurar como um método de pesquisa pelas possibilidades que abre na construção do conhecimento em uma perspectiva colaborativa e compreensiva dos saberes e valores que circulam na atividade laboral. As várias vertentes de autoconfrontação abrem esse processo de análise do trabalho, na medida em que convida ao estranhamento entre o que é feito, realmente, e tudo que atravessa o exercício de trabalhar. Não é toda a globalidade dessa experiência que é passível de análise, mas esse processo de explicitação da experiência (cujos limites não são relativos à incompetência linguística daqueles que trabalham) é construtivista, na medida em que podemos falar em desenvolvimento e fortalecimento profissional, posto que traga à consciência laboral o porquê e o como funciona o sistema sociotécnico no qual a atividade está imersa, bem como desvela alguns meandros da própria atividade para o sujeito que trabalha. Um processo de desnaturalização da atividade é, portanto, desencadeado pela autoconsciência do sujeito de que, para além do que foi programado, há sempre a intervenção daquele que trabalha. Essa consciência é o deslocamento na percepção entre aquilo que é o trabalho - suas normas produtivas, técnicas econômicas... - e como, em alguma medida, o trabalhador se coloca em face deles, consciente ou inconscientemente. A interatividade entre trabalhadores sobre o próprio trabalho, e destes com o pesquisador, pode representar uma desestabilização em relações sociais cristalizadas nas situações de trabalho analisadas, ao desvelar as dimensões subterrâneas dessa experiência. Tomada sem esse processo de autoconfrontação, a experiência pode vir à tona pouco problematizada, perdendo o interesse do ponto de vista da transformação do trabalho. Mas a experiência, assim abordada, explicita as aprendizagens formais ou informais construídas à prova das situações de trabalho, estando disponível para ser reativada por quem a detém em outros contextos. A Instrução ao Sósia possui qualidades formadoras para o trabalhador, seja porque valoriza seu ponto de vista nas transformações e melhorias no trabalho (ODDONE, RE, BRIANTE, 1981), seja porque o instrui pelo discernimento sobre os debates de normas que permeia todo trabalhar (SCHWARTZ, 2000a), seja porque desvela as dimensões subjetivas que saturam os gestos profissionais (CLOT, 1999). A formalização dessa experiência diária exigirá, portanto, esforço daquele que busca fazê-lo, para além de um domínio técnico daqueles que buscam implementálo, enquanto recurso metodológico.

Do ponto de vista da produção do conhecimento, esse material, rico em experiência 
laboral, traz aportes para outra produção científica sobre o trabalho. Nessa perspectiva, o que podemos compreender do trabalho realizado não pode ocorrer sem a contribuição dos trabalhadores, ainda que essa autoanálise do trabalho não possa ser esgotada, posto que nem toda a experiencia é analisável. Esse processo de investigação pela narrativa, pelo depoimento assim formulado não prescinde do diálogo com as contribuições dos diversos campos do conhecimento que estudam o trabalho. É o que podemos apreender dessa linhagem de pesquisas clínicas sobre trabalho que, para além de experimentação metodológica no sentido de adaptação do homem ao trabalho, abriu um campo de reflexão ético-política e epistemológica, no qual qualquer melhoria nas situações de trabalho deve se colocar no horizonte de promoção da saúde e do bem-estar dos trabalhadores.

Os autores Yves Clot (psicólogo) e Daniel Faïta (linguista fundador do dispositivo APST, nos anos 80) aprofundam o recurso de Instrução ao Sósia, elaborando as entrevistas em autoconfrontação simples ou cruzada, cujo objetivo é verbalizar sobre o trabalho, visam explicitar a relação dos trabalhadores com diversas dimensões de sua experiência (espaço, tempo, colegas, equipamentos etc.). O dialogismo de Bakhtin, pelo qual a enunciação é um acontecimento, é associado às bases da psicologia histórico-cultural de Vygotski (1997), fundamentando o dispositivo do lugar de fala da experiência laboral. A experiência do trabalho concreto será interrogada, explicitando a atividade do debate de normas como manancial político e epistemológico dos saberes produzidos no trabalho, e, para além deles, poderemos vislumbrar problemas mais gerais ligados à gestão e à organização geral da produção. Importante sublinhar que, na variação em autoconfrontação simples e cruzada, há uma intenção de explicitar, para além do realizado, o real da atividade (atividade latente, reprimida etc.: possíveis não realizados, conflitos vitais). Voltaremos ao assunto mais adiante.

Yves Schwartz, por sua vez, ampliará e aprofundará o alcance da proposta de construção de Comunidades Científicas Ampliadas (ODDONE; RE; BRIANTE, 1981) denominando-as Dispositivos Dinâmicos a Três Pólos (DD3P). Esses coletivos seriam necessários para construir conhecimento científico sem mutilar a atividade deste "si", "sujeito do recentramento": "para uma aprendizagem in situ das renormalisações locais" (SCHWARTZ, 2000a, p.658). É em diálogo com a obra de Oddone, Re e Briante (1981), e naquele contexto histórico francês que descrevemos acima, que os principais implicados no dispositivo APST - Análise Pluridisciplinar 
sobre Situações de Trabalho - se interrogam:

Com quais instrumentos conceituais abordar o domínio do trabalho e dos trabalhadores, ainda mais sendo verdade que, no que diz respeito ao núcleo central, o trabalho, ele mesmo, a abordagem não poderia ser balizada por procedimentos que não integrariam a consciência de uma diversidade não eliminável de abordagens? Nós o sugerimos: para conhecer uma realidade de trabalho, as generalidades são sempre mais ou menos falhas e é preciso uma aprendizagem quase clínica de conceitos próprios para decifrar. Quando dizemos: "trabalho noturno, novas tecnologias,siderurgia", como mensurar, exatamente, o que nestas noções faz avançar o conhecimento de uma realidade concreta e singular? Tal como o médico que, por mais conhecedor que seja de sintomas mórbidos, não pode fazer um diagnóstico sem o face a face com o doente e, da mesma forma, não podemos saber como utilizar e combinar os conceitos usuais do trabalho semo face a face com aqueles que vivem e desconstroem essas realidades, como o "trabalho noturno", a tarefa parcelizada da operária da indústria de confecção, a informatização dos trabalhos de secretariado, ou todas as outras realidades industriosas. Primeira razão para desejar uma Comunidade Científica Ampliada (SCHWARTZ, 1985, p.49). ${ }^{5}$

Os compartilhamentos entre pesquisadores e trabalhadores no contexto desses dispositivos permitem reconstruir a perspectiva da atividade, desvelando esses "usos de si" que nos deixam entrever um "sujeito". Essa seria uma via profícua de construção de conhecimento sobre o trabalho. Esse recentramento enraíza-se num "corpo-si" "entidade" biofisiológica, sóciohistórica e cultural. Coloca-se então o problema metodológico do como abordar este "si" em nossas pesquisas sobre otrabalho, visto que ele se expressa numa atividade que transgride todas asnormas e modelos conceituais que querem Ihe formalizar, congelar em modelos protocolares de análise científica nos conduzindoa registrá-lo em dualidades: corpo e alma; ser vivo e ser humano; consciente e inconsciente; linguístico e não verbal; individual e coletivo; o fazer e o

\footnotetext{
${ }^{5}$ Avec quels outils conceptuels aborder le domaine du travail et destravailleurs, tant il est vrai qu'en ce qui concerne le noyau central,le travail lui-même, l'approche ne saurait être balisée par desprocédures que n'intégreraient pas la concience d'une diversitéinéliminable des approches? On la sugerée: pour connaître une réalitéde travail, les généralités sont toujours plus ou moins fautives, ilfaut unapprentissage presque clinique des concepts propres àdéchiffrer. Quand on a dit : 'travail posté, nouvelle technologie, aciérie', comment mesurer exactement ce qui dans ces notions fait avancer la conanissance d'une réalitécocnrète et singulière? De mêmeque le médicin, tout savant qu'il soit sur les symptômes morbides, nepeut porter un diagnostic sans face à face avec le malade, de même, onne peut savoir comment utiliser et combiner les concepts ususels dutravail sans face à face avec ceux qui vivent et du même coup fontêtre ces réalités, comme 'le travail posté', la tâche parceliséee del'ouvrière de l'habillement, l'informatisation des travaux desecrétariat, ou touts autres réalité industrieuse. Première raison pourdésirer une communauté scientifique élargie (SCHWARTZ, 1985, p.49).
}

Periódico Horizontes - USF - Itatiba, SP - Brasil - e021030 
valorar; o raciocínio e o sentido etc. Poderíamos falar de uma atividade do "si" que recentra em saúde, numaperspectiva multimensional, seu meio de vida também multimensional. Tal recentramento em saúde se faz pela via dos saberes produzidos por esse homem singular e por sua capacidade de tomar decisões em função de valores de vida (éter da relação do ser vivo com o meio) disponíveis como patrimônio sociocultural pela humanidade que é a sua.

O termo Abordagem Ergológica do Trabalho aparecerá na obra Reconnaissances du travail - Pour une approche ergologique (SCHWARTZ, 1997). Tal como outras abordagens que Ihe são contemporâneas, oferece o que importa saber, na medida em que coloca o pesquisador em contato com os indivíduos inteiros e concretos, síntese que escapa a todo esforço analítico para conhecer os desdobramentos das transformações em curso na vida social e na organização do trabalho nas quais estes homens se inserem para trabalhar.

\section{Conceitos sob medida}

A Abordagem Ergológica do Trabalho aproxima a atividade industriosa por conceitos talhados no desafio de considerar sempre o geral e o particular, o macro e o micro, o individual e o coletivo, o histórico da longa duração e o aqui e o agora (SCHWARTZ, 1992). O Conceito de Uso de Si é um perfeito exemplo do arsenal conceitual da Abordagem Ergológica do Trabalho. Podemos entrevê-lo já em passagem rápida, na página 55 do livro L'homme producteur - Autour des mutations du travail et des savoirs (SCHWARTZ, 1985) ao falar das mutações em curso no mundo do trabalho francês àquela época:

Tudo parece indicar que a questão do lugar do homem no trabalho permanece, mais que nunca, central: a questão do investimento humano, no duplo sentido disto que é investido no homem por aqueles que o usam e disto que ele mesmo investiu nele mesmo, desloca-se sem cessar, permanecendo fundamental (p.55). ${ }^{6}$

Este conceito aparece bem delineado em capítulo publicado na obra supracitada Je: sur

\footnotetext{
${ }^{6}$ Tout semble indiquer que la question de la place de l'homme dans letravail reste plus que jamais entrale: la question del'investissement humain, au double sens de ce qui est investi enl'homme par ceux qui en usent et de ce qu'il y investi lui-même, sedéplace sans cesser de rester fondamentale.
} 
I'individualité: Approches pratiques/ouvertures marxistes, publicado, em 1987, pela Editora Messidor/Éditions Sociales. Nessa perspectiva, Schwartz aponta o ato humano de trabalho como sendoum lugar a partir do qual se pode abordar o problema da subjetividade, porquelugar da experiência do uso de si que fazem os homens noquotidiano das situações de trabalho que freqüentam. O homem produtoré sempre convocado em seus atos profissionais pelas configurações dassituações de trabalho. O exercício profissional implica os dramasinteriores desse homem produtor e assim ele se experimenta fazendo experiência de seu tempo histórico-cultural.

Nos interstícios da teia de exigências presentes no quotidiano dotrabalho, que se expressam como normas antecedentes, o homem produtoropera ressingularizações, pois ele as contorna, as absorve e/oureinventa, transgride, burla, re-aprende formas de ser e de realizartarefas prescritas por outrem. Trabalhando tais normas ele as modificae/ou modifica a si mesmo.

A gestão das variabilidades nas situações de trabalho, com vistas àrealização de objetivos definidos por outros nunca pode ser dissociada, no exercício mesmo do trabalho, de uma gestão de si mesmo,gerando um equilíbrio instável entre valores econômicos a seremproduzidos e valores realmente realizados. Assim, aspectos como cargade trabalho e fadiga nunca são dados, puramente objetivos,

que agridem do exterior o indivíduo; eles se negociam em uma alquimia sutil onde tudo depende da maneira pela qual o indivíduo, nas suas virtualidades singulares e seus limites, encontra o objetivo a realizar como ponto de apoio ou, ao contrário, restrição de seus possíveis particulares(SCHWARTZ, 2000b, p.37).

O ideal de saúde pensado por Canguilhem nos reenvia a algomuito próximo dessa dialética dos usos de si na Abordagem Ergológica do Trabalho e propicia a onipresença dos valores, fundando as construções desses usos entre a saúde e otrabalho que faz "Je" e que buscam conhecer os estudos das clínicas aqui discutidas:

Essa capacidade de ser norma instituinte, na qual a vida se prolongano homem, atravessa e é atravessada pela experiência privada dahominização e pelo acesso ao patrimônio social pelas formas históricasde individualidade. $O$ ideal de saúde em que esta capacidade tornaforma e conteúdo tem, portanto as heranças particulares, trabalhadaspermanentemente pelos possíveis e pelos ideais coletivos, mais oumenos mudos ou explícitos, do momento histórico. Cada 
momento de umaconfrontação entre os saberes, o ideal de saúde de um indivíduo e ascoerções micro e macroscópicas são, portanto, singulares e ninguém podesubstituir aquele que faz a experiência para julgar de seus limites ede seus horizontes. Assim, cada configuração onde os homens têm deviver coloca-lhes questões novas onde, através do uso que fazem delesmesmos, experimentam também seu ser (SCHWARTZ, 2000b, p.48).

Esse "si" é pensado como esse" sujeito" que age entre o trabalhoprescrito e o trabalho realmente executado. É esse "si" o "sujeito"

em torno do qual é preciso se recentrar, o qual é preciso considerar os projetos, os objetivos, posto que é assim que poderemos "preencher" os mecanismos infinitesimais, prodigiosamente rápidos, de um sistema nervoso sempre 'proativo', como compreendê-lo, com quais conceitos analisá-lo? Ser especificamente humano e ao mesmo tempo prolongamentosem descontinuidade radical de uma centração que atravessa já o reinoanimal. Como os "objetivos" deste sujeito, engajado em múltiplos"níveis" de vida, em níveis infinitamente variável de organicidade, dehumanidade, de consciência, de relação à linguagem, de história e de cultura, podem preencher este jogo radicalmente instituído em relaçãoao meio [...]. Com quais instrumentos conceituais abordar estas trajetórias enigmáticas, as quais nenhum destes níveis escapa? Onde o mesmo - esta "estrutura fundamental da atividade"marca a outra -esta diversidade dos níveis de gozo da vida - e reciprocamente (SCHWARTZ, 2000a, p.646).

Esse uso de si pode estar contido num movimento do olhar de um caixa de supermercado em direção à fila do seu guichê para controlar seu próprio ritmo, em um meio de trabalho em crescente racionalização, informatização e introdução de administração por objetivos.Isso que Schwartz chama de "recentramento" é o processo de apropriação, pelo homem, das condições dadas nas situações de trabalho, meio no qual se encontra. Esta relação não é mecânica. $O$ homem a recentra sob condições disponíveis. Neste hiato constitui-se o ideal de saúde com o qual Canguilhem procura fundar a significação do normal pela análise filosófica da vida, entendida como atividade de oposição à inércia e à indiferença.

Essa compreensão do "si" desvela como ele, o "si", transgride as fronteiras do pessoal, do social e do cultural, podendo se instalar nas estratégias biológicas, neurológicas e cerebrais desse trabalhador. Esse "recentramento" não pode ser compreendido a partir de uma "bricolagem" de estudos científicos nas mais diversas áreas, por justaposição de conhecimentos disciplinares. Desafia-nos a ultrapassar as fronteiras entre a natureza e a cultura, pois o "si" transgride todas 
as fronteiras dos cortes epistêmicos, impedindo-nos de conhecê-lo pela via dos conceitos produzidos nesses terrenos. Uma epistemologia de conhecimento desta realidade singular exige "conceitos de relações" (SCHWARTZ, 1992, p.221) que, por articular ingredientes contraditórios, deixam entrever como se engendram as configurações históricas. No caso do trabalho, espreitar os usos que esse "si" faz e permite fazer de si mesmo não são compreensíveis no a prioridos conceitos científicos desenvolvidos nas diversas ciências. Compreendê-lo nos convoca à instauração de um trabalho mais que multidisciplinar, interdisciplinar, mirando o terreno do transdiciplinar. Os recentramentos do "si" não são passíveis de serem fisgados em modelos científicos, nem mesmo em modelos transdisciplinares (se eles puderem existir). Tal compreensão implica uma sensibilidade (profissionalidade) ergológica e nos obriga a cunhar conceitos que conectem dimensões díspares: subjetivo-objetivo, macro-micro...

\section{Ingredientes da competência mobilizados nos usos de si}

Evoluções contemporâneas nas formas de governo do trabalho evidenciam a dimensão ética que atravessa todo ato e todas as situações de trabalho cotidianas. Segundo Schwartz (1996, 2000a) os valores compõem o rol dos ingredientes da competência, não sendo nunca algo determinado apenas pela imposição normativa das regras e dos objetivos dos gestores do trabalho. Existe uma dinâmica de re-singularização, um "recentramento" que implica trabalho dos valores, perpassando a atividade industriosa. O sentido atribuído ao próprio trabalho determina a implicação do homem produtor com a tarefa a ser desempenhada, com as soluções encontradas para os problemas enfrentados no quotidiano. E, esse sentido, não pode ser objeto de prescrição normativa por parte dos gestores.

Poderíamos falar de um trabalho dos valores perpassando a realização das atividades de trabalho. Poderíamos falar aqui também, de aprendizagem de valores que se inscrevem na aprendizagem de qualquer ofício ou função. Na análise da atividade de docentes, por exemplo, podemos constatar uma implicação entre as dimensões pedagógicas, ético-políticas, os valores e princípios que caracterizam e explicam o estilo próprio de cada um, os princípios que regem e personificam-se através do ato de educar.

Os valores, como ingredientes que compõe as competências de uma pessoa,remetem- 
nos ao sentido atribuído ao trabalho pelo homem produtor. Nesse leito, ancora-se a motivação para o saber. A relação com o saber, é outro ingrediente que povoa a competência do homem produtor: o desejo de maior qualidade no seu trabalho favorece o esforço de aprendizagemnecessário para buscar conhecimento e saber, indispensáveis para tanto. Estes dois últimos ingredientes estão fora do alcance das prescrições, das normatizações gerenciais numa situação de trabalho dada. Não se pode prescrever amor ao saber ou ao bem comum. Essas manifestações se constroem nas mais diversas experiências de vida e trabalho do produtor e nos projetos herdados de coletividades as quais integrou.

Finalmente, a competência para gerir e criar sinergias entre individualidades e coletivos de trabalho. Esse ingrediente está sempre presente em trabalhos coletivos, sendo necessário para assegurar a complementaridade dos diversos ingredientes da competência, a saber: implica avaliar a si mesmo, suas competências e as dos colegas, a fim de ajustar as estratégias coletivas de ação. Em todas as situações de trabalhoexistem cooperações. Essas sinergias são mais ou menos favorecidas pela organização do trabalho. São produto de interação informal ou intencional em espaços de trabalho ou em outros ambientes de convivência. Essa sinergia de coletivos de trabalho é tecida em pequenas negociações cotidianas para realizar um projeto em comum em constante devir: faz-se, a cada momento, pela ação de um sujeito que, "ao negociar suas compreensões, aliena parte do que elaborou em nome do que o grupo tece ali, simultaneamente, e que esse tecer é também um fazer e desfazer contínuos" (CUNHA, 2003, p.119).

Mas justamente esses três ingredientes para todo agir humano competente, alvo das formas de governo mais solicitadas pelos gestores, deixam espaço para uma tensão permanente, um equilíbrio cada vez mais instável entre os objetivos prescritos alhures e os objetivos do homem produtor e das pequenas coletividades encontradas em toda situação de trabalho. E são, paradoxalmente, essas formas de governo do trabalho que colocam na ordem do dia uma reunificação entre trabalho e trabalhador singular. Poderíamos falar de individualização crescente via "gestão pelas competências", fruto dessa evolução nas concepções gerenciais, mas preferimos destacar, nesse contexto, o quanto essa reunificação trabalho-trabalhador individual, fragiliza e torna mais instável o equilíbrio nas formas de governo do trabalho pelos gestores.

É nesse cenário de crescente "invisibilidade" do trabalho prescrito que os valores de 
quem trabalha podem "minar" os planos gerenciais de maiores ganhos de produtividade. Mas é também esse processo, pelo que ele implica dos aspectos subjetivos do homem produtor, que pode promover uma maior pressão sobre a carga mental do trabalho, provocando adoecimentos. O conceito de "uso de si" pode ser um bom instrumento de leitura dos dramas que operam no exercício do trabalho e do trabalho dos valores que toda atividade industriosa implica. O trabalho é, então, esse híbrido composto pelo uso que eu faço, quero e posso fazer de mim mesmo, num contexto do uso heterodeterminadoque me é imposto pelas normas de trabalho, pelas normas socioculturais de convivência, pelos usos mercantis da minha força de trabalho. Tanto no aprendizado de um ofício como no exercício do mesmo, nós podemos verificar a inscrição deste "uso de si" numa história, num universo de normas, de saberes, de valores que não foram criados por nós e que não nos permite dispor de nós mesmos, livremente. Marx fala em surdina nesta afirmação, quando aponta que todo homem faz história, mas não em condições que eles escolhem.

\section{Da experiencia à atividade}

O trabalho, segundo uma acepção clássica, é sequência de operações a serem realizadas, independentemente de quem irá realizá-las. Entretanto, a ergonomia nos convida a observar o trabalho nos meios profissionais ligando condições materiais e organizacionais a partir do ponto de vista da atividade real de trabalho. A Ergonomia da Atividade (GUÉRIN et al., 1997) vislumbrará um trabalhador ativo no interior mesmo de uma cadeia de montagem, entre o prescrito e o real, já na passagem dos anos 60 e 70. O termo Ergo vem do grego, significando ação e obra, possibilitando entender o trabalho como atividade reguladora individual e coletiva que faz funcionar o sistema em seus acontecimentos aleatórios de todas as ordens, através das antecipações e das gestões simultâneas de múltiplos horizontes temporais que se apresentam numa situação produtiva. O objetivo é compreender como o trabalho se realiza, compreender seu movimento, para tirar as consequências necessárias tanto para uma renovada concepção dos sistemas técnico-organizacionais quanto para a vida em comum (GUÉRIN et al., 1997).

Para tanto, uma distinção fundamental é aquela do trabalho prescrito e do trabalho 
real. O trabalho prescrito é tudo aquilo que é definido, antecipadamente, pela organização e fornecido ao trabalhador para que o mesmo defina, organize, realize e regule seu trabalho. 0 trabalho real é o trabalho tal como ele se realizou concretamente, no local de trabalho. Entre o trabalho prescrito e o trabalho real se inscrevem múltiplas variabilidades relativas ao processo de trabalho (meios, matéria e atividade) e que não podem ser, previamente, antecipados. Nessa fenda epistêmica que abriu a ergonomia - distância entre o prescrito e o real -, o termo atividade emerge,(re)apropriado da psicologia histórico-cultural, notadamente em Leontiev (1975).

Para a análise ergonômica, trabalho prescrito e o trabalho real podem ser analisados em termos de tarefa e atividade, ainda que tais definições sejam muito próximas. É preciso diferenciá-las para analisar, de modo mais profundo, o que seja a atividade humana em situação de trabalho. Isto porque as atuais transformações nos modelos de gestão do trabalho podem chegar mesmo a prescrever a própria atividade laboral (vide modelos de gestão da qualidade). Mas não é somente por isso, pois a análise da atividade do trabalhador mostra que o mesmo pode chegar a prescrever suas tarefas (lidando com as margens de autonomia deixadas pela organização) e, no entanto, ainda assim seria necessário diferenciar o que foi prescrito (para o trabalhador e por ele mesmo) antecipadamente e o que foi realmente realizado. Mas ainda assim, se nos limitarmos a esse nível de apreensão da realidade, dimensões importantes da atividade nos escapariam, pois nossa análise deixaria de fora a dimensão afetiva, cognitiva e física da atividade realizada em toda sua complexidade.

A análise da atividade pode ser feita a partir de gestos, posturas corporais, deslocamentos no espaço de trabalho. Pode ainda compreendida no diálogo com o trabalhador durante a realização do trabalho através de verbalizações nas quais ele explica suas ações, de modo que possamos compreender em que situação de trabalho ele se encontra e na relação que mantém com as variáveis do contexto. Podemos também, através de observação desvelar aspectos que geram conflito e stress na atividade do trabalhador. A Ergonomia trata estes aspectos como 'observáveis' pois desvelam elementos da atividade do trabalhador: avaliação que faz da situação na qual se encontra, componentes afetivos e raciocínios desenvolvidos no enfrentamento e resolução de conflitos e problemas.

A análise da atividade é centrada no que faz o trabalhador, suas ações, seu 
funcionamento, suas intenções, seus valores e competências, seus saberes, os sentidos que o mesmo atribui ao seu trabalho e as tarefas que lhe são atribuídas para realizar. Nesse sentido, compreende uma análise da tarefa (atribuída por outrem ou formulada por ele mesmo), mas é mais do que isso, pois deve incluir o modus operandi do trabalhador face às situações de trabalho, também, em toda sua complexidade uma vez que contendo relações sociais, relações de trabalho, condições de trabalho produzidas historicamente. É, portanto, no espaço entre o trabalho prescrito e o trabalho, efetivamente, realizado que se inscreve a atividade humana em meios profissionais.

O termo atividade reintegra, aos poucos, as dimensões psicológicas, sociais e culturais, tomando o próprio ato de trabalho como "encarnado", prenhe de sentidos, significados, razões teleológicas, valores, motivos e crenças ao sujeito humano e às suas ações no trabalho, significante e motivado, dimensões evacuadas pelo racionalismo científico. As perspectivas clínicas do trabalho desvelam a atividade industriosa como um objeto de estudo complexo, cuja compreensão e análise exigem enfoque multidisciplinar. Abordar o trabalho, levando-se em conta as múltiplas dimensões humanas implicadas no seu exercício é um desafio em termos de produção de conhecimento, pois aspectos políticos, biológicos, psicológicos, socioculturais, econômicos e jurídicos precisam ser levados em conta, bem como a sua realidade no espaço e no tempo.

O conceito de atividade oferece um quadro teórico construtivista e sociointeracionista para pensar o trabalho, exigindo um esforço conceitual em repensar e problematizar as categorias de análise dos diversos campos científicos. Partindo de temas e problemas particulares, diversas disciplinas que se ocupam do trabalho humano vêm confluindo para questões em torno da atividade de trabalho. Em verdade, abordam problemas diversos do mundo do trabalho, alguns deles tradicionais (mutações, qualificação, emprego, saúde, autogestão, participação, serviços, etc.) sob uma mesma perspectiva: da atividade de trabalho. Nesta perspectiva, o acento é dado ao termo "atividade", no trabalho enquanto atividade humana, em seu processo de realização aqui e agora. Com efeito, o trabalho pode ser tratado sob as mais diversas perspectivas, ao sabor dos conceitos e métodos adotados em cada disciplina, mas a base comum é dada pelo termo atividade.Desafios epistemológicos renovados interrogam os produtores de saberes sobre o trabalho, exigindo rompimento das fronteiras

Periódico Horizontes - USF - Itatiba, SP - Brasil - e021030 
rígidas impetradas pelos recortes disciplinares, exigindo diálogos interdisciplinares entre aqueles que conhecem, em profundidade, parcelas epistemologicamente bem recortadas do trabalho.

O interesse das contribuições clínicas aqui analisadas neste artigo está no fato exigirem re-incorporar os sujeitos que trabalham nas análises sobre trabalho. Mas se esse interesse central pela atividade exige um esforço de "observar o trabalho com uma lupa", implicando num certo distanciamento das abordagens clássicas da sociologia e da economia do trabalho, não implica, entretanto, abandonar os problemas abordados nessas disciplinas, mas em atribuir um olhar de tipo novo para as questões macrossociais ou estruturais que as mesmas revelam em seus estudos. Esse mergulho na atividade para compreendê-la em situações concretas renova o tratamento de questões já abordadas pela sociologia/economia em uma abordagem macro. Todavia, muitas vezes faltam às abordagens empíricas voltadas à análise e compreensão da trama cotidiana do trabalho uma visão mais ampla, impondo-se uma necessária articulação entre aspectos micro e macro da realidade social.

O termo atividade vai assumindo a centralidade teórico-metodológica em detrimento da ideia de uma experiência dos modos de produção que faz todo trabalhador, central na obra de Oddone, Re e Briante (1981), fonte fundamental para a Clínica da Atividade e para a Abordagem Ergológica do Trabalho. Trabalhar é mais do que seguir normas prescritas, portanto, trabalhar é arbitrar entre possíveis nas situações laborais: "a eficiência transita pelo uso que os assalariados fazem deles mesmos em resposta às solicitações do seu meio de vida" (CLOT, 1992, p.104) ${ }^{7}$.

Schwartz prospecta o termo cunhado no idealismo alemão (de Kant a Hegel) como trabalho abstrato do espírito no movimento da história e rastreia suas acepções em Marx (Teses sobre Feuerbach e $\mathrm{O}$ Capital) de onde fora recuperado pela psicologia histórico-cultural. $\mathrm{Na}$ Abordagem Ergológica do Trabalho, o termo ganha acepção de agir sintético pelas dramáticas de um corpo-si, "operador de transgressões entre os diversos campos e registros da experiência humana" (SCHWARTZ, 2000b, p.24) entre corpo e alma, produção e valores, diversas linguagens, individual e coletivo, consciente-não consciente e inconsciente, orgânico - sociocultural e histórico... Não há como decorticar, analiticamente, essas dimensões da enigmática sinergia dos heterogêneos no corpo-si, onde há múltiplas possibilidades de vivenciar paixões em meio à

\footnotetext{
${ }^{7}$ L'efficience transite par l'usage que les salariés fontd'eux mêmes en réponse aux solicitations de leur milieu devie (Thése de YC, p.104).
}

Periódico Horizontes - USF - Itatiba, SP - Brasil - e021030 
normatividade vital (prenhe de valores) que fazem para o Homem o sentido da sua vida singular.

Repensar o trabalho requer rompimento com a exterritorialidade entre pesquisador e experiência da atividade laboral, problematizando a produção científica a partir do que seja a experiência do trabalho real nas mais diversas situações, confrontando saberes produzidos no trabalho e nos diversos discursos científicos e revelando zonas de incultura mútua. A Abordagem Ergológica do Trabalho, tomando a Ergonomia como uma propedêutica, saberá retomar a pertinência da formação de Comunidades Científicas Ampliadas (ODDONE, RE, BRIANTE, 1981) na forma de Dispositivos Dinâmicos a Três Pólos. Estes últimos são imprescindíveis para compreender o que está em jogo na atividade industriosa - enigmática, e que não pode ser apreendida por nenhuma disciplina específica (SCHWARTZ, 2000b; 2015), uma vez que transgride, extrapola, desvirtua, transborda os cortes epistemológicos das disciplinas para compreender as dimensões humanas. Será necessário pensar "conceitos de relações" que ofereçam vistas às interfaces disciplinares ou que tragam dimensões transdisciplinares para compreender a atividade industriosa de um corpo-si, corpo histórico se debatendo com normas e reinventando as formas de vida em permanência, criando alternativas no aqui e no agora dos micros espaços das situações de trabalho, renormalizando de modo dramático o que se põe como destino a viver.

Yves Clot buscava compreender as relações entre as formas sociais de individualidade e as formas psíquicas na passagem dos anos 80 para os anos 90 (CLOT, 1987, p.310), juntamente com os autores da coletânea Je, sur l'individualité. A atividade era afirmada claramente por seu poder matricial das relações sociais objetivas na formação da personalidade, da individualidade do homem produtor. Leontiev (1975) é referenciado por seu modelo de atividade, o que não será jamais negado nos desenvolvimentos posteriores da Clínica da Atividadenos oferecendo uma acepção específica do termo atividade. Clot se apropria de aspectos estruturantes desse modelo teórico que traz uma rica dialética entre objetivo de uma ação (partevisível) e motivo de uma atividade. A atividade precede e antecipa a ação, mas nãose esgota nela. A atividade é isso que antecipa, planifica a ação e é o quea ação não pode realizar completamente. Essa clivagem, presente na Tese de 1992, se traduz por atividade/subjetividade (não há recobrimento total entre ambas as dimensões), sendo mantida nos desenvolvimentos posteriores da clínica da Atividade.

Bakthin (2006) auxiliará a Clínica da Atividade a compreender tensões inelimináveis entre

Periódico Horizontes - USF - Itatiba, SP - Brasil - e021030 
o sentido e o significado através da dialética de gênero (onde se ancora o sujeito da enunciação) e o estilo (que indica uma reapropriação nos gêneros da norma linguística e na construção de sentido pelo enunciador). O gênero (meio de ação, memória social do trabalho que determina as condições iniciais do ato singular) e o estilo, que é singular, se alimenta desta memória social, mas que aporta novidade ao renová-la pela via do seu desenvolvimento/singular-universal.Nessa perspectiva, reforça-se a diferenciação entre atividade e subjetividade. Esta última configura-se em um movimento interno à atividade, pensada enquanto funções psíquicas superiores (afetos, emoções, sentimentos, cognição, percepção...) que, mergulhadas na ação, sob inspiração do monismo de Espinosa (Clot, 2015), funde dimensões psíquicas (socioculturais e historicamente determinadas) e somáticas. A experiência do trabalho se produziria aí nesse imbricamento, pleno de conflitos vitais e possíveis não realizados, entre atividadereal e o para além/aquém do realizado - atividade latente, reprimida etc.

O trabalho, sendo uma atividade triplamente dirigida, é conduzida pelo homem produtor, através do objeto da tarefae na relação com o outro, nas situações produtivas. Esse processo é dinâmico, sendo que a atividade não é apenas aquilo que é realizado, mas o que não é. A atividade real do sujeito extrapola os limites da atividade realizada. O real da atividade é também aquilo que não se faz, atividade impedida, que não podemos fazer, que gostaríamos de fazer sem conseguir, os fracassos (atividade contrariada, o que gostaríamos de ter feito que pensamos ou sonhamos em fazer... bem como o que fazemos para não fazer o que está lá pra ser feito ou ainda o que fazemos sem o desejar. Atividade impedida que traz conflito para o homem produtor em situação laboral. Não há recobrimento possível entre a atividaderealizada e a atividade real, esta, uma experiência maior que faz o homem produtor. Dito de outra forma, a tarefa não recobre, completamente, a atividade. Há dissonâncias e incomensurabilidades entre o motivo da atividade, o objetivo da ação e os meiosde operação, permeando e estruturando a potência de agir.

O trabalho é ação e sua função psicológica vem do fato que ele coloca o sujeito à prova de suas obrigações práticas e vitais em direção aos outros e a si mesmo. Mas a própria ação deve ser compreendida como um trabalho que se pode operar por intermédio do desenvolvimento das atividades do sujeito. Essa atividade retira o sujeito de si the fornecendo a ocasião de recomeçar sua história subjetiva. O Eu reaparece como produto de uma história. É historiador 
de sua própria temporalidade na qual não determina todos os vetores e dimensões: "redator de um compromisso identificatório no seio de um funcionamento desdobrado, regido pelo princípio de mudança e um princípio de permanencia [...] ocupado por um trabalho de historicização, enigmático e constante, dos arquivos marcantes de sua história" (CLOT, 1992, p.835). Daí a importância de intervir nas situações de vida e trabalho ampliando as zonas proximais, liberando conflitos, propiciando e potencializando o desenvolvimento do sujeito.

Estamos bem distantes de colocar um termo nas questões levantadas no início dos anos 80 pelos autores do Je, sur l'individualié, nisto que podemos chamar uma herança comum pela Abordagem Ergológica do Trabalho e pela Clínica da Atividade. Estas clínicas contribuem, largamente, na compreensão do trabalho, desvendando os meandros da atividade industriosa por meio de conceitos específicos. Deixa-nos, entretanto, a angústia de sabermos o quão impossívelé apreendê-la em termos cognoscíveis. O debate permanece em aberto, posto que:

- o conceito de atividade elucida o potencial do modo marxiano de apreender o trabalho em epítetos (concreto-abstrato, simples-complexo, material-imaterial, produtivo-improdutivo, valor de uso-valor de troca), mas também problematiza seus limites;

- as microscópicas do agir engendram transformações e reconfigurações históricas que podem levar ao ultrapassamento das situações de trabalho. Entretanto, permanece difícil articular o nível mais micro das atividades humanas no interior das organizações às ações coletivas e às transformações societárias mais gerais. Talvez porque permaneçam obscuros os elos entre dimensões clínicas desveladas pelo conceito de atividade situada e os temas da alienação-emancipação-autonomia dos trabalhadores no e pelo trabalho;

- o entendimento do "EU" permanece em tensão subliminar com o sujeito da psicanálise (patrimônio que não pode ser negado como experiência subjetiva individual, estruturante na formação do ser social), ainda mal acomodado nas teorizações e conceitos dessas clínicas e;

Enquanto pesquisadores brasileiros e latino-americanos, na medida em que herdarmos dessas abordagens, conceitos, modos de pensar e de pesquisar os problemas, de intervir no trabalho de outrem, herdamos também o que se encontra em aberto e que convoca nosso engajamento ético-político, científico e cultural.

Periódico Horizontes - USF - Itatiba, SP - Brasil - e021030 


\section{HSE}
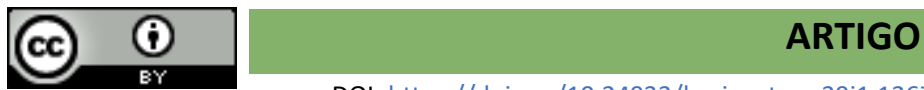

\section{Referências}

BAKHTIN, M. Marxismo e filosofia da linguagem. 12. ed.São Paulo: Hucitec, 2006.

BENDASSOLLI, P.; SOBOLL, L. A. (orgs.). Clínicas do trabalho: novas perspectivas para compreensão do trabalho na atualidade. São Paulo: Atlas, 2011.

CANGUILHEM, G. Millieu et normes de l'homme autravail. Cahiers Internationaux de Sociologie, v.3. 1947, p.120-136.

CANGUILHEM, G. O normal e o patológico. Trad. Maria Thereza R. de C. Barrocas e Luiz Otávio F. Barreto. 4. ed. ampliada, Rio de Janeiro: Forense Universitária, 1995.

CLOT, Y. Vygotski avec Spinoza, au-delà de Freud. Revue philosophique de la France et de l'étranger, tome 140, 2015/2, p.205-224.

CLOT, Y. La fonction psychologique du travail. Paris: PUF, 1999.

CLOT, Y. Le travail entre activité et subjectivité. 1992, 855f. Thèse (Doctorat en Philosophie) Aix-Marseille Université, Aix-en-Provence, France, 1992.

CLOT, Y. Postface. Le marxisme à l'épreuve. In: BERTRAND, D; CASANOVA, A.; CLOT, Y; DORAY, B.; HURTEL, F.; SCHWARTZ, Y.; SÈVE, L.; TERRAIL, J-P. (orgs.). Je: sur l'individualité: approches pratiques/ouvertures marxistes. Paris: Messidor/Editions Sociales, 1987. p.299-312.

CUNHA, C. M. O trabalho docente em equipe: tramas e processos vivenciados e significados atribuídos: a experiência do projeto de educação de trabalhadores - PET. 2003. $228 \mathrm{f}$. Dissertação (Mestrado em Educação) - FaE/UFMG, Belo Horizonte, 2003.

DORAY , B. De laproduction à lasubjectivité. Réperages pour une dialectique de forms. In: BERTRAND, D; CASANOVA, A.; CLOT, Y; DORAY, B.; HURTEL, F.; SCHWARTZ, Y.; SÈVE, L.; TERRAIL, J-P. (orgs.). Je: sur l'individualité: approches pratiques/ouvertures marxistes. Paris: Messidor/Editions Sociales, 1987, p.117-153.

DORAY, B. Da produção à subjetividade - referências para uma dialética das formas. In: SILVEIRA, P.; DORAY, B. (orgs.). Elementos para uma teoria marxista da subjetividade. São Paulo: Vértice, Editora Revista dos Tribunais, 1989, p.77-108.

GUÉRIN, F.; DURAFFOURG, J.; LAVILLE, A; DANIELLOU, F.; KERGUELEN, A. Comprendre le travail pour le transformer - la pratique de l'ergonomie. Lyon, França : Editions de l'ANACT, 1997.

LABICA, G. Karl Marx: les thèse sur Feuerbach. Paris: PUF, 1987. 
LEONTIEV, A. Activité, conscience, personalité. Paris: Editions du Progrès, 1975.

NEVES, T. I.; PORCARO, L. A.; CURVO, D. R. Saúde é colocar-se em risco: normatividade vital em Georges Canguilhem. Saude Soc. São Paulo, São Paulo, v.26, n.3, p.626-637, 2017.

ODDONE, I.; RE, A.; BRIANTE, G. Redécouvrir l'expérience ouvrière - vers une autre psychologie du travail? Paris: Méssidor/Éditions Sociales, 1981.

SCHWARTZ, Y. Vygotski/Spinoza. Revue Philosophique de la France et de l'Étranger, tome 140, n.4, p.561-566, 2015.

SCHWARTZ, Y. Le paradigme ergologique ou um métier de philosophe. Toulouse, França: Octarès Éditions, 2000a.

SCHWARTZ, Y. Philosophie et ergologie. Paris: Bulletin de la Societé Française de Philosophie, 2000b.

SCHWARTZ, Y. Trabalho e uso de si. Revista Pro-Posições, v.1, n.5, jul. 2000c.

SCHWARTZ, Y. (org.) Reconnaissances du travail - pour une approche ergologique. Paris: PUF, 1997.

SCHWARTZ, Y. Ergonomie, philosophie et exterritorialité. In: DANIELLOU, F. (orgs.). L'ergonomie en quête de ses principes - Débats épistémologiques. Toulouse: Octarès Editions, 1996, p.141182.

SCHWARTZ, Y. Travail et philosophie - convocations mutuelles. Toulouse: Ocatarès, 1992.

SCHWARTZ, Y. Expérience et connaissance du travail. Paris: Messidor/Editions Sociales, 1988.

SCHWARTZ, Y. Travail et travailleurs en questions. In: SCHWARTZ, Y., FAÏTA, D. (orgs.) L'Homme producteur - autor des mutations du travail et des savoirs. Paris: Messidor/Éditions Sociales, 1985. p.27-55.

SÈVE, L. Penser avec Marx aujourd'hui. L'homme,tome II. Paris: La Dispute, 2008.

SÈVE, L. La personalité en gestation. In: BERTRAND, D; CASANOVA, A.; CLOT, Y; DORAY, B.; HURTEL, F.; SCHWARTZ, Y.; SÈVE, L.; TERRAIL, J-P. (orgs.). Je: sur l'individualité: approches pratiques/ouvertures marxistes. Paris: Messidor/Editions Sociales, 1987, p.209-247.

VERNES, P. M.; SCHWARTZ, Y.; CHASSE, M.; SERIS, J. P.; DEJOURS, C. Rapport sur la thèse d'Yves Clot: le travail entre subjectivité et activité. Aix-en-Provence: Aix-Marseille Université, 26 novembre, 1992.

VYGOTSKI, L. Pensée et langage. Trad. F. SEVE. Paris: La Dispute, 1997. 
Recebido em setembro 2020.

Aprovado em maio 2021. 